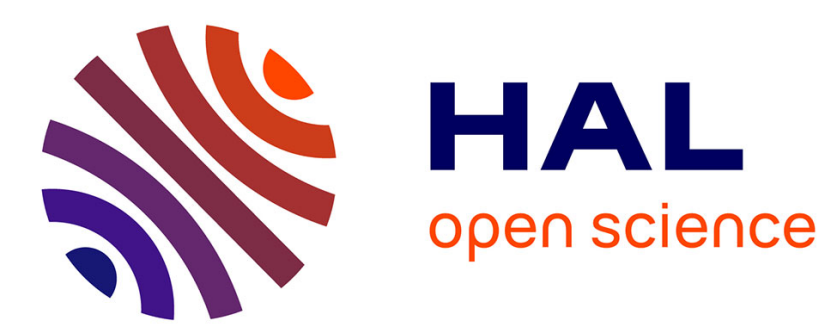

\title{
Electrophysiological evidence for the hierarchical organization of auditory change detection in the human brain
}

Sabine Grimm, Carles Escera, Lavinia Slabu, Jordi Costa-Faidella

\section{- To cite this version:}

Sabine Grimm, Carles Escera, Lavinia Slabu, Jordi Costa-Faidella. Electrophysiological evidence for the hierarchical organization of auditory change detection in the human brain. Psychophysiology, 2011, 48 (3), pp.377-384. 10.1111/j.1469-8986.2010.01073.x . hal-01863520

\section{HAL Id: hal-01863520 \\ https://hal.science/hal-01863520}

Submitted on 28 Aug 2018

HAL is a multi-disciplinary open access archive for the deposit and dissemination of scientific research documents, whether they are published or not. The documents may come from teaching and research institutions in France or abroad, or from public or private research centers.
L'archive ouverte pluridisciplinaire HAL, est destinée au dépôt et à la diffusion de documents scientifiques de niveau recherche, publiés ou non, émanant des établissements d'enseignement et de recherche français ou étrangers, des laboratoires publics ou privés. 
Electrophysiological evidence for the hierarchical organization of auditory change detection in the human brain

Sabine Grimm ${ }^{1}$, Carles Escera ${ }^{1}$, Lavinia Slabu ${ }^{1}$, Jordi Costa-Faidella ${ }^{1}$

${ }^{1}$ Institute for Brain, Cognition and Behavior (IR3C), University of Barcelona, Catalonia-Spain

\section{Corresponding author:}

Carles Escera, PhD, Professor

Department of Psychiatry \& Clinical Psychobiology

Faculty of Psychology

University of Barcelona

P. Vall d'Hebron 171

08035 Barcelona * Catalonia-Spain

Tel: +34933125048

Fax: +34 934021584

email: cescera@ub.edu 


\begin{abstract}
:
Auditory change detection has been associated to the mismatch negativity (MMN), an eventrelated potential (ERP) occurring at 100-250ms after the onset of an acoustic change. Yet, singleunit recordings in animals suggest much faster novelty-specific responses in the auditory system. To investigate change detection in a corresponding early time range in humans, we measured the Middle Latency Response (MLR) and MMN during a controlled frequency oddball paradigm. In addition to MMN, an early effect of change detection was observed at about 40ms after change onset reflected in an enhancement of the Nb component of the MLR. Both MMN and the Nb effect were shown to be free from confounding influences such as differences in refractoriness. The finding implies that early change detection processes exist in humans upstream of MMN generation which supports the emerging view of a hierarchical organization of change detection expanding along multiple levels of the auditory pathway.
\end{abstract}


The ability to detect new events in the acoustic environment is vitally important, as they might call for a prompt adaptive response. This requires that regularities in the acoustic input are modeled and kept in memory, so that deviant or contextually new stimuli violating the regularity representations can be detected. Processes of deviance detection have traditionally been associated with a particular component, the mismatch negativity (MMN; Escera, 2007; Näätänen, Gaillard, \& Mäntysalo, 1978; Näätänen, 2007) of the human event-related potential (ERP). This brain response is usually obtained with the auditory oddball paradigm comparing activity elicited by a frequently repeated stimulus (standard) to that elicited by an interspersed rare stimulus containing a feature variation (deviant). In that way, $\mathrm{MMN}$ can be obtained for violations of simple feature rules, as for example in the case of frequency, location, or intensity deviants, but it is also elicited for sounds violating more complex regularities (e.g. phonetic contrasts, abstract regularities defining the relationship between sounds etc.; for an overview, see (Picton, Alain, Otten, Ritter, \& Achim, 2000). Thereby an MMN response is generated at 100 $250 \mathrm{~ms}$ from deviance onset by sources located bilaterally in the supratemporal brain region in the vicinity of auditory cortex (Alho, 1995; Näätänen \& Alho, 1995; Maess, Jacobsen, Schröger, \& Friederici, 2007). Additional prefrontal contributions have been reported in several studies (Deouell, 2007).

The underlying processes involve the modeling and storage of the acoustic regularities and can not merely be explained by different states of refractoriness of feature-specific neurons responding to the standard or deviant (Näätänen, Jacobsen, \& Winkler, 2005; see also Jääskeläinen et al., 2004). This has been shown by means of a controlled oddball paradigm for a variety of deviant types including location (Schröger \& Wolff, 1996), frequency (Jacobsen \& Schröger, 2001), and duration (Jacobsen \& Schröger, 2003) deviants. 
In the controlled paradigm, the deviant stimulus from the oddball block is compared to a physically identical sound occurring with the same probability as the deviant in a context of different randomly presented equiprobable stimuli. Thus, the differential response is ensured not to be due to the differences in stimulus probability and associated differences in the state of refractoriness of neural populations, but is reflecting "true" deviance detection based on a regularity representation stored in auditory sensory memory.

Nevertheless, our understanding of the neural mechanisms underlying auditory deviance detection is still fragmentary. A step forward in this direction has been recently provided by studies of single-unit recordings in anesthetized animals. Indeed, the majority of neurons of the cat's primary auditory cortex exhibit a property termed stimulus-specific adaptation (SSA), that is, they reduce significantly their discharge rate after a few repetitions of the standard tone, but show fast robust responses to novel ${ }^{1}$ stimuli that slightly differ in their feature properties from the standard (Ulanovsky, Las, \& Nelken, 2003; Ulanovsky, Las, Farkas, \& Nelken, 2004). Despite sharing similar characteristics with the human MMN, the early latency of these noveltyspecific neural responses (circa $20 \mathrm{~ms}$ ) suggests that they are not directly equivalent, but rather lie upstream of MMN generation (von der Behrens, Bäuerle, Kössl, \& Gaese, 2009). Furthermore, very recent single-unit studies have shown that neurons in the inferior colliculus in the rat (Malmierca, Cristaudo, Pérez-González, \& Covey, 2009; Pérez-González, Malmierca, \& Covey, 2005) and in the barn owl (Reches \& Gutfreund, 2008) and neurons in the medial geniculate body of the thalamus (Anderson, Christianson, \& Linden, 2009; Antunes, Covey, \& Malmierca, 2010) exhibit similar SSA to that found in the cat A1, suggesting that deviance

\footnotetext{
${ }^{1}$ Note, that the term novel is used here in a more general meaning referring to contextually new or deviant information.
} 
detection in the auditory system can be found even before the information reaches the auditory cortex.

A comprehensive interpretation of these animal and human results is suggestive of two important aspects regarding the auditory system: 1) that deviance detection is a key principal expanding along the auditory pathway from the lower levels of the brainstem to high-order areas of the cerebral cortex; 2) that the generation of the MMN recorded from the human scalp is the consequence of a cascade of deviance detection processes at these different levels. Yet, a unified picture of these two lines of research, in humans and animals, is missing.

In the present study we aimed to test the hypothesis of a "pervasive auditory novelty system" by investigating processes of auditory change detection in humans on multiple time scales including the time range corresponding to the novelty responses observed in auditory cortex of animals. Therefore, we measured aside from the MMN component an earlier portion of the ERP, the human Middle Latency Response (MLR) during a controlled oddball paradigm. The MLR is characterized by a sequence of waveforms in the range $12-50 \mathrm{~ms}$ from sound onset, labeled as P0, Na, Pa, and Nb (Picton, Hillyard, Krausz, \& Galambos, 1974), composed of activation in subcortical, and primary and secondary auditory cortices (Deiber, Ibanez, Fischer, Perrin, \& Mauguiere, 1988; Liegeois-Chauvel, Musolino, Badier, Marquis, \& Chauvel, 1994; Yvert, Crouzeix, Bertrand, Seither-Preisler, \& Pantev, 2001; Yvert et al., 2002). The MLR and MMN responses were measured to frequency deviants $(800 \mathrm{~Hz}$ and $3730 \mathrm{~Hz}$, in separate conditions) occurring in an oddball block and the responses were compared to those elicited by physically identical stimuli when they had the role of a standard in a "reversed" oddball block, and when occurring equiprobably amongst other four low-probability tones (control condition; Figure 1). 
The setup of the EEG recordings was tailored to provide the possibility to extract the MLR components $\mathrm{P} 0, \mathrm{Na}, \mathrm{Pa}, \mathrm{Nb}$ and the long-latency component $\mathrm{MMN}$ in parallel analyses. Our results revealed "true" deviance detection at a latency of $40 \mathrm{~ms}$ in humans, i.e., by the $\mathrm{Nb}$ waveform of the MLR, supporting the idea of a multistage comparison system for change detection along the auditory pathway in humans.

\section{Methods}

\section{Participants}

Twenty healthy, normal-hearing students (18-31 years, 11 female) participated in the experiment for payment ( $6 €$ per hour). All participants had normal hearing at both ears with a mean hearing threshold below $25 \mathrm{~dB}$ tested for the five frequencies used in the experiment. The experimental protocol was approved by the Ethical Committee of University of Barcelona, and was in accordance with The Code of Ethics of the World Medical Association (Declaration of Helsinki). Participants gave written informed consent before the experiment.

\section{Materials}

Auditory sequences were composed of pure sinewave sounds of $50 \mathrm{~ms}$ duration including a $5 \mathrm{~ms}$ rise and a $5 \mathrm{~ms}$ fall time. Sounds were presented binaurally via headphones at an intensity level of $50 \mathrm{~dB}$ above the individual hearing threshold as measured at the beginning of each experiment. The stimulus onset-to-onset interval was set to $293 \mathrm{~ms}$. The oddball sequence contained a frequent standard sound occurring with a probability of 0.80 and a rare frequency deviant occurring randomly with a probability of 0.20 . In one of two conditions, the standard frequency was $1200 \mathrm{~Hz}$ and the deviant frequency was $800 \mathrm{~Hz}$ (low frequency condition). In the 
second, high frequency condition, the standard frequency was $2580 \mathrm{~Hz}$ and the deviant frequency $3730 \mathrm{~Hz}$. Corresponding to each of the oddball blocks, a reversed sequence was introduced in which the roles of deviant and standard stimuli were switched. Additionally, a control condition was presented intermixing randomly tones of five different frequencies (800, $1200,1780,2580,3730 \mathrm{~Hz}$ ), each occurring with a probability of 0.2 from which the two extreme stimuli were taken as control tones for the low and high frequency condition, respectively (see Figure 1). This was done to preclude refractoriness confounds (i.e., the assumption that the deviant stimulus will elicit a stronger response per se, as it occurs with a much smaller probability than the standard and therefore would find feature-specific neural populations in a less refractory state than those responding to the standard stimulus (Schröger \& Wolff, 1996).

\section{Procedure}

During the experiment, subjects were seated comfortably in an electrically shielded and soundattenuated chamber. They were instructed to relax and to watch a silent movie with subtitles ignoring the auditory stimulation. In total, 920 trials per deviant, standard and control stimulus were delivered. The three conditions (oddball, reversed oddball, and control) were split into a total number of 16 blocks of approximately 5 minutes each, which were presented in random order. After each block, subjects had a short break allowing for movements, after every fourth block a five minutes break for rest was introduced. 


\section{Electroencephalographic Recording}

The electroencephalogram (EEG) was recorded continuously from 9 tin scalp electrodes referenced to an electrode placed on the tip of the nose. Electrodes were mounted according to the 10-20 system using an elastic cap (ECI Electro Cap) at the positions F3, F4, Fz, C3, C4, Cz, $\mathrm{Pz}$ and the left and right mastoids. Additionally, eye movements were measured bipolarly by two electrodes placed above and below the right eye (vertical electrooculogram, VEOG) and two electrodes placed at the outer canthi of each eye (horizontal electrooculogram, HEOG). The electrode signals were amplified using a SynAmps amplifier (Neuroscan), online bandpassfiltered from 0.05 to $500 \mathrm{~Hz}$ and digitized with a sampling rate of $2500 \mathrm{~Hz}$. Off-line data were re-referenced to the left mastoid.

\section{EEG analysis}

For the analysis in the long-latency range of the ERP, data was filtered off-line with a Kaiserwindowed sinc bandpass filter (beta=5.658) from 0.6 to $35 \mathrm{~Hz}$. Epochs of $400 \mathrm{~ms}$ including a $100 \mathrm{~ms}$ pre-stimulus baseline were averaged separately for the deviant, standard and control stimulus in the two frequency conditions. Any trial with an amplitude variation larger than 80 $\mu \mathrm{V}$ was excluded from further analysis. Mean amplitudes of MMN were extracted at the electrode $\mathrm{Cz}$ from a 30-ms time window around the grand-average peak latency ranging from 90 to $120 \mathrm{~ms}$ as derived from the difference waveforms between deviant and standard, and deviant and control stimuli respectively. A repeated measures ANOVA including the factors Stimulus Type (deviant, standard, control) and Tone Frequency (low, high) was calculated on the mean amplitudes in the MMN time window. If appropriate, pairwise differences between single levels of factors were tested applying repeated measures contrasts. 
For the MLR analysis, data was filtered with a Kaiser-windowed sinc bandpass filter (beta=5.658) from 15 to $200 \mathrm{~Hz}$. Epochs of $150 \mathrm{~ms}$ including a $50 \mathrm{~ms}$ pre-stimulus baseline were averaged. Any trial with an amplitude variation larger than $80 \mu \mathrm{V}$ was excluded from further analysis. The components $\mathrm{P} 0, \mathrm{Na}, \mathrm{Pa}$, and $\mathrm{Nb}$ of the MLR were extracted for the three stimulus types (deviant, standard, controls) and the two frequency conditions. Individual peak latencies were derived from the largest peak in the time windows 7-17 ms (P0), 19-29 ms (Na), 26-36 ms $(\mathrm{Pa})$, and 37-47 ms $(\mathrm{Nb})$, respectively. As mean amplitudes are known to be more reliable than peak amplitudes (Picton et al., 2000), analyses of the components' amplitudes were based on the mean voltage measured in a 4-ms time window centered on the respective mean grand-average peak latency elicited by the deviant, standard and control stimuli at the electrode Cz. For the high frequency stimuli, $\mathrm{P} 0$ peaked in the grand-average waveforms at $10 \mathrm{~ms}, \mathrm{Na}$ at $23 \mathrm{~ms}, \mathrm{~Pa}$ at 28 $\mathrm{ms}$, and $\mathrm{Nb}$ at $38 \mathrm{~ms}$. For the low frequency stimuli, the respective grand-average peak latencies were at $12 \mathrm{~ms}(\mathrm{P} 0), 24 \mathrm{~ms}(\mathrm{Na}), 32 \mathrm{~ms}(\mathrm{~Pa})$, and $42 \mathrm{~ms}(\mathrm{Nb})$ after tone onset.

For each component a repeated measures ANOVA including the factors Stimulus Type (deviant, standard, control) and Tone Frequency (low, high) was calculated on MLR peak latencies and mean amplitudes. If appropriate, pairwise differences between single levels of Stimulus Type were tested applying repeated measures contrasts.

A result was considered significant when $\mathrm{p}<0.05$ using a two-tailed analysis. Bonferroni correction was used for all multiple pairwise contrasts as well as for testing on multiple MLR components. The partial eta squared $\left(\eta_{\mathrm{p}}{ }^{2}\right)$ is reported in addition to $\mathrm{F}$ - and p-values. 


\section{Results}

ERPs recorded in 20 participants displayed the typical series of components in response to the standard, deviant, and control tones in the low (Figure 2 a) and in the high (Figure 2 b) frequency conditions. Focusing on the long-latency range of the ERPs, a prominent MMN was obtained peaking at about $105 \mathrm{~ms}$ after tone onset. In the MLR, the characteristic P0-Na-Pa-Nb complex was displayed in all experimental conditions (Figure 2, bottom). MLR peak latencies are given in Table 1. Table 2 shows the mean amplitude values for each MLR component in the 4-ms latency windows around the grand-average peaks as given above.

\section{Long-latency components of the ERP}

First, data were analyzed with respect to the long-latency range of ERP contrasting evoked responses to standard, deviant, and control stimuli for both the low and high frequency tones. In the time window around the MMN peak from 90 to 120 ms, deviant ERPs displayed a sharp negative potential, this being of less negative amplitude for control ERPs and even positive for standard ones. Amplitude differences for the three stimulus types were statistically significant in this latency window $\left(\mathrm{F}(2,38)=74.15, \mathrm{p}<0.001, \eta_{\mathrm{p}}{ }^{2}=0.80\right)$. The repeated measures ANOVA revealed no main effect of Tone Frequency $\left(F(1,19)=3.51, \mathrm{p}<0.077, \eta_{\mathrm{p}}{ }^{2}=0.16\right)$, but an interaction of Tone Frequency and Stimulus Type $\left(F(2,38)=11.99, \mathrm{p}<0.001, \eta_{\mathrm{p}}{ }^{2}=0.39\right)$. Tones differences between the deviant and standard (repeated measures contrasts for low frequency: $\mathrm{F}(1,19)=124.11$, corrected $\mathrm{p}<0.001, \eta_{\mathrm{p}}{ }^{2}=0.87$; for high frequency: $\mathrm{F}(1,19)=45.32$, corrected $\mathrm{p}<0.001, \eta_{\mathrm{p}}{ }^{2}=0.71$ ) and somewhat smaller differences between deviant and control (repeated measures contrasts for low frequency: $F(1,19)=49.71$, corrected $\mathrm{p}<0.001, \eta_{\mathrm{p}}{ }^{2}=0.72$; for high 
Hierarchical organization of auditory change detection

frequency: $\mathrm{F}(1,19)=24.47$, corrected $\left.\mathrm{p}<0.001, \eta_{\mathrm{p}}{ }^{2}=0.56\right)$ were present. The interaction resulted from the fact that in the low frequency condition control and deviant responses showed more negative mean amplitudes than in the high frequency condition, whereas mean amplitudes for standard ERP had more positive values than in the high frequency condition.

\section{MLR components of the ERP}

Second, we examined data with respect to the MLR of the ERP. Peak latencies and main amplitudes of the components $\mathrm{P} 0, \mathrm{Na}, \mathrm{Pa}, \mathrm{Nb}$ were contrasted for the three stimulus types (deviant, standard, control) and the two frequencies (low, high).

Peaks elicited by the high frequency tones showed shorter latencies than the low frequency ones (see Table 1) as reflected in a main effect of Tone Frequency for the components $\mathrm{Na}(\mathrm{F}(1,19)=$ 9.81, corrected $\left.\mathrm{p}=0.022, \eta_{\mathrm{p}}{ }^{2}=0.34\right), \mathrm{Pa}\left(\mathrm{F}(1,19)=17.01\right.$, corrected $\left.\mathrm{p}=0.002, \eta_{\mathrm{p}}{ }^{2}=0.47\right)$, and $\mathrm{Nb}\left(\mathrm{F}(1,19)=13.502\right.$, corrected $\left.\mathrm{p}=0.006, \eta_{\mathrm{p}}{ }^{2}=0.42\right)$, but not for $\mathrm{P} 0(\mathrm{~F}(1,19)=1.83$, corrected $\left.\mathrm{p}=0.77, \eta_{\mathrm{p}}{ }^{2}=0.09\right)$. Neither latency differences between standard, deviant, and control stimuli, nor any interaction between Stimulus Type and Tone Frequency were observed (F's $<3.5$, corrected p's $\left.>0.17, \eta_{\mathrm{p}}^{2}<0.16\right)$. 
A main effect of Tone Frequency on component's mean amplitudes, in terms of larger mean amplitudes elicited by the low compared to the high frequency tones, was found for the components $\mathrm{Na}\left(\mathrm{F}(1,19)=8.11\right.$, corrected $\left.\mathrm{p}=0.040, \eta_{\mathrm{p}}{ }^{2}=0.30\right), \mathrm{Pa}(\mathrm{F}(1,19)=22.30$, corrected $\left.\mathrm{p}=0.003, \eta_{\mathrm{p}}{ }^{2}=0.54\right)$, and $\mathrm{Nb}\left(\mathrm{F}(1,19)=11.41\right.$, corrected $\left.\mathrm{p}=0.012, \eta_{\mathrm{p}}{ }^{2}=0.38\right)$ but not for P0 $\left(\mathrm{F}(1,19)=4.10\right.$, corrected $\mathrm{p}=0.23, \eta_{\mathrm{p}}{ }^{2}=0.18$; see Table 2$)$. Modulations through novelty, in terms of a main effect of Stimulus Type on the components' mean amplitude, were observed for the time window of the $\mathrm{Nb}$ component $\left(\mathrm{F}(2,38)=6.84\right.$, corrected $\left.\mathrm{p}=0.012, \eta_{\mathrm{p}}{ }^{2}=0.27\right)$, with this main effect of Stimulus Type being absent for the earlier components $(\mathrm{P} 0: \mathrm{F}(2,38)=2.31$, corrected $\mathrm{p}=0.452, \eta_{\mathrm{p}}{ }^{2}=0.11, \mathrm{Na}: \mathrm{F}(2,38)=1.11$, corrected $\mathrm{p}=1.000, \eta_{\mathrm{p}}{ }^{2}=0.06, \mathrm{~Pa}: \mathrm{F}(2,38)=$ 1.35 , corrected $\mathrm{p}=1.000, \eta_{\mathrm{p}}{ }^{2}=0.07$; cf. Figure 3$)$. Post-hoc repeated measures contrasts confirmed differences in the $\mathrm{Nb}$ latency window between deviant and standard responses $\left(\mathrm{F}(1,19)=9.98\right.$, corrected $\left.\mathrm{p}=0.010, \eta_{\mathrm{p}}{ }^{2}=0.34\right)$ and between deviant and control responses $\left(\mathrm{F}(1,19)=6.57\right.$, corrected $\left.\mathrm{p}=0.038, \eta_{\mathrm{p}}{ }^{2}=0.26\right)$. Amplitude modulations through Stimulus Type did not interact with the effects of Tone Frequency for any of the components (F's $<1.1$, corrected p's $\left.=1.000, \eta_{\mathrm{p}}^{2}<0.06\right)$.

\section{Discussion}

The results of the present study have revealed that "true" auditory deviance detection can take place in humans as early as $40 \mathrm{~ms}$ after the onset of a deviant feature presented in an otherwise repetitive sequence of standard stimuli. This was supported by the fact that a characteristic amplitude modulation of the MLR component $\mathrm{Nb}$ (peaking at about 38-42 ms) was obtained 
depending on the deviant status of a stimulus. The $\mathrm{Nb}$ response was larger for a stimulus when it occurred as a frequency deviant than the response elicited by the same stimulus when it occurred in the role of a standard or a control tone. In the later portion of the ERP, we additionally obtained a clear MMN peaking at about $105 \mathrm{~ms}$ after sound onset when contrasting deviant against standard and control responses.

The MMN is the typical marker of deviance detection known to reflect a memory-based process of comparing incoming stimuli with an internal model derived from the regularities in the previous stimulation. A respective control condition is required (Schröger \& Wolff, 1996) to ensure that any deviance-related modulation obtained in an oddball paradigm is truly memorybased and not merely reflecting differences in the response strength of feature-specific neural populations (that are more refractory in case of a repeatedly presented standard frequency than in case of a rarely presented deviant one). Of similar importance is the control for physical stimulus properties. Particularly the MLR is a sequence of components whose latencies and amplitudes are systematically influenced by physical stimulus characteristics (Picton et al., 1974); as reflected in the latency and amplitude differences for the MLR components $\mathrm{Pa}, \mathrm{Na}$ and $\mathrm{Nb}$ between low and high frequency tones in the present study, which is congruent with previous reports in the literature (Kraus \& McGee, 1988; Thornton, Heneghan, James, \& Jones, 1984). Taking into account these points, the $\mathrm{MMN}$ and the enhancement of $\mathrm{Nb}$ obtained in the present study are due to the informational status carried by a stimulus in its respective context and thus reflect true deviance detection rather than confounds by stimulus properties or refractoriness. Thus, it can be concluded that besides the typical MMN component also the middle-latency portion of the ERP (which has so far barely been analyzed in studies applying the oddball paradigm) is sensitive to stimulus novelty. This goes in line with a few recent results challenging 
the long-held belief that early auditory processing reflected in the MLR solely depends on the physical properties of an incoming stimulus. Sonnadara and colleagues (2006) reported an enhanced Na component of the MLR peaking at $25 \mathrm{~ms}$ after sound onset for location deviants compared to standard click sounds thus indicating an early effect of stimulus rareness. Yet, the lack of a respective control condition does not ascertain conclusively whether those results can be attributed to "true" deviance detection. Furthermore, modulations of MLR amplitudes by sensory gating (Müller, Keil, Kissler, \& Gruber, 2001), self-initiation of a stimulus (Baess, Widmann, Roye, Schröger, \& Jacobsen, 2009), task requirements (Woldorff \& Hillyard, 1991) and even by sound segregation processes (Dyson \& Alain, 2004) have been shown, altogether underlining the complex nature of auditory processing already in its initial phase.

From animal studies we have indication that deviance detection can arise already at this early steps of auditory processing. For the first time, Ulanovsky et al. (2003, 2004) comprehensively described the activity of novelty neurons in the primary auditory cortex (A1) of the cat. These neural responses share a variety of properties with the MMN for which they have been regarded its single-neuron correlate. Both the firing of novelty neurons and MMN are pre-attentive responses whose magnitude is inversely related with the deviant probability and positively related with the degree of deviance, both show already local sequence effects, their latencies are similarly influenced by deviant probability and both responses are localized to the auditory cortex (Nelken \& Ulanovsky, 2007).

On the other hand, however, there are remarkable differences in timing between the firing onset of novelty units (at about 20 ms from stimulus onset; Pérez-González et al., 2005; Ulanovsky et al., 2004) and the peak latency of the MMN which is contradicting the view that the first directly accounts for the latter (von der Behrens et al., 2009). Therefore the activity of novelty neurons 
has been interpreted as a change detection process in PAC that lies upstream of later MMN generation. The modulation of $\mathrm{Nb}$ by stimulus deviance found here, exemplifies that those "upstream" activities also exist in the human auditory system and that they can be identified in the ERP with a respectively tailored setup. It remains open whether the deviance-related $\mathrm{Nb}$ enhancement is more directly linked to the activity of novelty neurons in PAC. At least the two share partly similar origins as the transition of components $\mathrm{Pa}$ to $\mathrm{Nb}$ is supposed to be generated by cortico-cortical connections mediating auditory information from PAC to the superior temporal gyrus (STG; Yvert et al., 2002). Yet, only the simultaneous use of the different techniques in future studies might permit to disambiguate the temporal relationship between single-cell firing and the potentials measured over larger auditory fields.

Eventually, the present study confirms that deviance detection is implemented on multiple levels during auditory processing in the human brain. In order to integrate these results into a conceptual framework, we here propose that deviance detection and the underlying processes of modeling invariant input are a pervasive property of the auditory system, expanding from lower levels along the auditory pathway to high-order areas of the cerebral cortex. This property allows us to react quickly to new events in our environment and crucially shapes our perception by sharpening its sensitivity to changes in the incoming information. Within this framework, it can be assumed that the generation of $\mathrm{MMN}$ is a consequence of a cascade of deviance detection processes occurring at hierarchically lower levels. Accordingly, we can hypothesize that this function is organized in a hierarchical manner, so that deviance-related responses to simplefeature changes as used here are detected at the lower levels of the novelty system's hierarchy whereas more complex levels of regularity will be encoded in higher levels and thus in the latency range of MMN only. Alternatively, one could speculate about more profound differences 15 
in the functional significance of the two levels of deviance processing, with the earlier possibly being related to a mechanism of auditory predictions (compare, Bendixen, Schröger, \& Winkler 2009; Winkler, Denham, \& Nelken, 2009), and the later level being related to regularity updating which has been proposed previously as one of the functional roles of MMN (Winkler, Karmos, \& Näätänen, 1996; Winkler, 2007). Without question, future studies are needed to clarify the functional significance of the different levels of deviance processing.

To summarize, we report here a new electrophysiological marker of auditory deviance detection that indicates the auditory system's rapid response to rare and unexpected sounds. This response resembles in origin and latency very much the recently described responses of so-called novelty neurons found in the cat's auditory cortex and complements our picture of the functional organization of the auditory system. The presence of different markers of deviant processing in two time ranges of the ERP in the present study strongly supports the idea of a hierarchically organized system serving auditory deviance detection. 
Hierarchical organization of auditory change detection

Acknowledgement: This work was supported by the program Consolider-Ingenio 2010 (grant number CDS2007-00012), the National Program for Fundamental Research (grant number PSI2009-08063), a Juan de la Cierva grant to Sabine Grimm (grant number JCI-2009-04401) by the Spanish Ministry of Science and Innovation, and the ERANET NEURON project PANS (grant number EUI2009-04086). The authors thank Marc Recasens for his help during data acquisition. 


\section{References}

Alho, K. (1995). Cerebral generators of mismatch negativity (MMN) and its magnetic counterpart (MMNm) elicited by sound changes. Ear and Hearing, 16(1), 38-51.

Anderson, L. A., Christianson, G. B., \& Linden, J. F. (2009). Stimulus-specific adaptation occurs in the auditory thalamus. The Journal of Neuroscience, 29(22), 7359-7363.

Antunes, F. M., Covey, E., \& Malmierca, S. M. (2010). Is there stimulus-specific adaptation in the auditory thalamus? In E. A. Lopez-Poveda, A. R. Palmer \& R. Meddis (Eds.), The neurophysiological bases of auditory perception. New York: Springer.

Baess, P., Widmann, A., Roye, A., Schröger, E., \& Jacobsen, T. (2009). Attenuated human auditory middle latency response and evoked 40-hz response to self-initiated sounds. The European Journal of Neuroscience, 29(7), 1514-1521.

Bendixen, A., Schröger, E., \& Winkler, I. (2009). I Heard That Coming: Event-Related Potential Evidence for Stimulus-Driven Prediction in the Auditory System. The Journal of Neuroscience, 29(26):8447-8451.

Deiber, M. P., Ibanez, V., Fischer, C., Perrin, F., \& Mauguiere, F. (1988). Sequential mapping favours the hypothesis of distinct generators for $\mathrm{Na}$ and $\mathrm{Pa}$ middle latency auditory evoked potentials. Electroencephalography and Clinical Neurophysiology, 71(3), 187-197.

Deouell, L. Y. (2007). The frontal generator of the mismatch negativity revisited. Journal of Psychophysiology, 21(3-4), 188-203. 
Hierarchical organization of auditory change detection

Dyson, B. J., \& Alain, C. (2004). Representation of concurrent acoustic objects in primary auditory cortex. The Journal of the Acoustical Society of America, 115(1), 280-288.

Escera, C. (2007). The mismatch negativity 30 years later: How far HaveWe come? Journal of Psychophysiology, 21(3-4), 129-132.

Jääskeläinen, I. P., Ahveninen, J., Bonmassar, G., Dale, A. M., Ilmoniemi, R. J., Levanen, S., et al. (2004). Human posterior auditory cortex gates novel sounds to consciousness. Proceedings of the National Academy of Sciences of the United States of America, 101(17), 6809-6814.

Jacobsen, T., \& Schröger, E. (2001). Is there pre-attentive memory-based comparison of pitch? Psychophysiology, 38(4), 723-727.

Jacobsen, T., \& Schröger, E. (2003). Measuring duration mismatch negativity. Clinical Neurophysiology, 114(6), 1133-1143.

Kraus, N., \& McGee, T. (1988). Color imaging of the human middle latency response. Ear and Hearing, 9(4), 159-167.

Liegeois-Chauvel, C., Musolino, A., Badier, J. M., Marquis, P., \& Chauvel, P. (1994). Evoked potentials recorded from the auditory cortex in man: Evaluation and topography of the middle latency components. Electroencephalography and Clinical Neurophysiology, 92(3), 204-214.

Maess, B., Jacobsen, T., Schröger, E., \& Friederici, A. D. (2007). Localizing pre-attentive auditory memory-based comparison: Magnetic mismatch negativity to pitch change. NeuroImage, 37(2), 561-571. 
Malmierca, M. S., Cristaudo, S., Pérez-González, D., \& Covey, E. (2009). Stimulus-specific adaptation in the inferior colliculus of the anesthetized rat. The Journal of Neuroscience, 29(17), 5483-5493.

Müller, M. M., Keil, A., Kissler, J., \& Gruber, T. (2001). Suppression of the auditory middle-latency response and evoked gamma-band response in a paired-click paradigm. Experimental Brain Research, 136(4), 474-479.

Näätänen, R. (2007). The mismatch negativity. where is the big fish? Journal of Psychophysiology, 21(3-4), 133-137.

Näätänen, R., \& Alho, K. (1995). Generators of electrical and magnetic mismatch responses in humans. Brain Topography, 7(4), 315-320.

Näätänen, R., Gaillard, A. W., \& Mäntysalo, S. (1978). Early selective-attention effect on evoked potential reinterpreted. Acta Psychologica, 42(4), 313-329.

Näätänen, R., Jacobsen, T., \& Winkler, I. (2005). Memory-based or afferent processes in mismatch negativity (MMN): A review of the evidence. Psychophysiology, 42(1), 25-32.

Nelken, I., \& Ulanovsky, N. (2007). Mismatch negativity and stimulus-specific adaptation in animal models. Journal of Psychophysiology, 21(3-4), 214-223.

Pérez-González, D., Malmierca, M. S., \& Covey, E. (2005). Novelty detector neurons in the mammalian auditory midbrain. The European Journal of Neuroscience, 22(11), 2879-2885. 
Picton, T. W., Alain, C., Otten, L., Ritter, W., \& Achim, A. (2000). Mismatch negativity: Different water in the same river. Audiology \& Neuro-Otology, 5(3-4), 111-139.

Picton, T. W., Bentin, S., Berg, P., Donchin, E., Hillyard, S. A., Johnson, R.,Jr, et al. (2000). Guidelines for using human event-related potentials to study cognition: Recording standards and publication criteria. Psychophysiology, 37(2), 127-152.

Picton, T. W., Hillyard, S. A., Krausz, H. I., \& Galambos, R. (1974). Human auditory evoked potentials. I. evaluation of components. Electroencephalography and Clinical Neurophysiology, $36(2), 179-190$.

Reches, A., \& Gutfreund, Y. (2008). Stimulus-specific adaptations in the gaze control system of the barn owl. The Journal of Neuroscience, 28(6), 1523-1533.

Schröger, E., \& Wolff, C. (1996). Mismatch response of the human brain to changes in sound location. Neuroreport, 7(18), 3005-3008.

Sonnadara, R. R., Alain, C., \& Trainor, L. J. (2006). Occasional changes in sound location enhance middle latency evoked responses. Brain Research, 1076(1), 187-192.

Thornton, C., Heneghan, C. P., James, M. F., \& Jones, J. G. (1984). Effects of halothane or enflurane with controlled ventilation on auditory evoked potentials. British Journal of Anaesthesia, 56(4), $315-323$.

Ulanovsky, N., Las, L., Farkas, D., \& Nelken, I. (2004). Multiple time scales of adaptation in auditory cortex neurons. The Journal of Neuroscience, 24(46), 10440-10453. 
Ulanovsky, N., Las, L., \& Nelken, I. (2003). Processing of low-probability sounds by cortical neurons. Nature Neuroscience, 6(4), 391-398.

von der Behrens, W., Bäuerle, P., Kössl, E. H., \& Gaese, B. H. (2009). Correlating stimulus-specific adaptation of cortical neurons and local field potentials in the awake rat. The Journal of Neuroscience, 29(44), 13837-13849.

Winkler, I. (2007). Interpreting the mismatch negativity (MMN). Journal of Psychophysiology, 21, $147-163$.

Winkler, I., Denham, S., \& Nelken, I. (2009). Modeling the auditory scene: predictive regularity representations and perceptual objects. Trends in Cognitive Sciences, 13(12), 532-540.

Winkler, I., Karmos, G., \& Näätänen, R. (1996). Adaptive modeling of the unattended acoustic environment reflected in the mismatch negativity event-related potential. Brain Research, 742, $239-252$.

Woldorff, M. G., \& Hillyard, S. A. (1991). Modulation of early auditory processing during selective listening to rapidly presented tones. Electroencephalography and Clinical Neurophysiology, $79(3), 170-191$.

Yvert, B., Crouzeix, A., Bertrand, O., Seither-Preisler, A., \& Pantev, C. (2001). Multiple supratemporal sources of magnetic and electric auditory evoked middle latency components in humans. Cerebral Cortex, 11(5), 411-423. 
Hierarchical organization of auditory change detection

Yvert, B., Fischer, C., Guenot, M., Krolak-Salmon, P., Isnard, J., \& Pernier, J. (2002). Simultaneous intracerebral EEG recordings of early auditory thalamic and cortical activity in human. The European Journal of Neuroscience, 16(6), 1146-1150. 


\section{Figure Captions}

Figure 1. Experimental design. Stimuli were presented in three types of blocks: (a) oddball blocks; (b) reversed oddball blocks interchanging the roles of deviant and standard frequencies; and (c) control blocks containing equiprobable tones of five different frequencies. The squares symbolize single tones. Sound duration was $50 \mathrm{~ms}$, the stimulus onset-to-onset interval was set to $293 \mathrm{~ms}$.

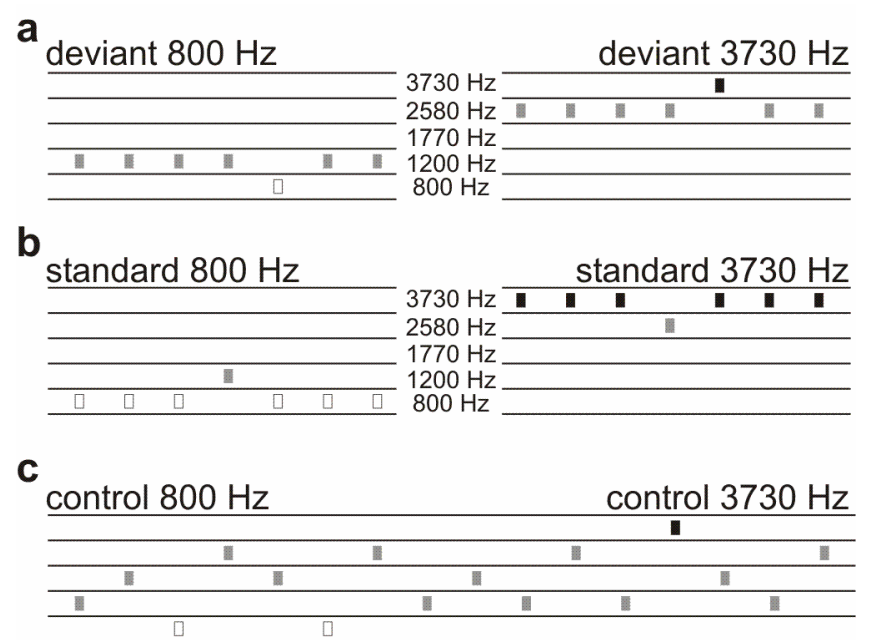

H Tone duration: $50 \mathrm{~ms} \longmapsto \mathrm{SOA}: 293 \mathrm{~ms}$

Figure 2. Grand-average evoked potentials of 20 subjects (a) for the low frequency tones and (b) for the high frequency tones. On the left of each panel the auditory evoked potentials for deviant (grey solid), standard (black dashed), and control sounds (black solid) are shown including middle and long latency portions of the ERP applying a $0.6 \mathrm{~Hz}$ high-pass filter. In the middle column of each panel the data filtered in the MLR range for the three stimulus conditions are presented. A statistical difference on the $\mathrm{Nb}$ component peaking at about $40 \mathrm{~ms}$ was observed as indicated by the asterisks in the zoom below. In the right column of each panel data filtered in 
Hierarchical organization of auditory change detection

the long-latency range (LLR) of the ERP are shown. In the difference waveforms below, a clear MMN is present for the deviant and standard (black dashed) as well as for the deviant and control comparison (black solid).

a low frequency tones $(800 \mathrm{~Hz})$

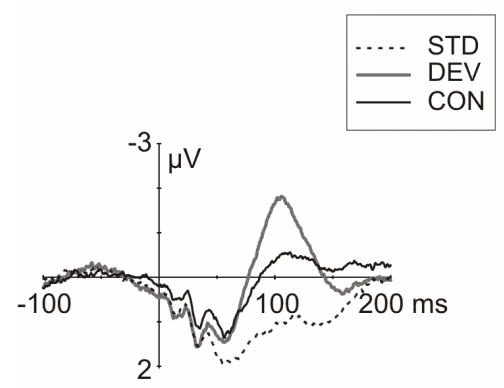

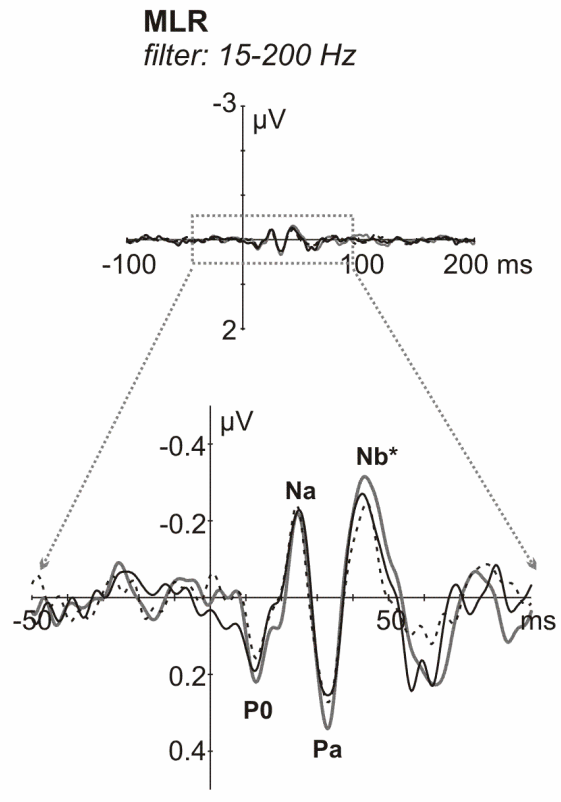

b high frequency tones $(3730 \mathrm{~Hz})$

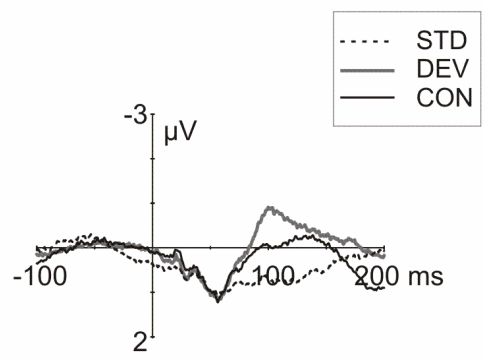

LLR

filter: $0.6-35 \mathrm{~Hz}$

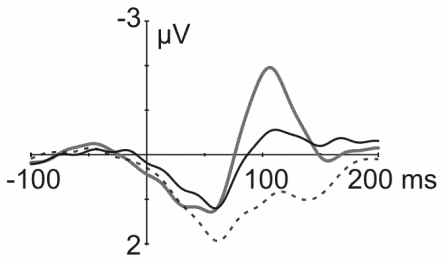

Difference waves:

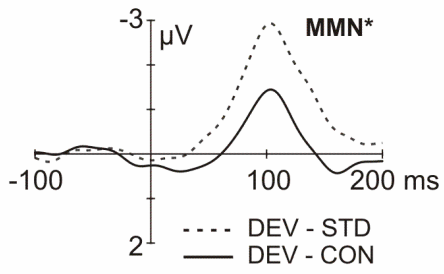

LLR

filter: $0.6-35 \mathrm{~Hz}$

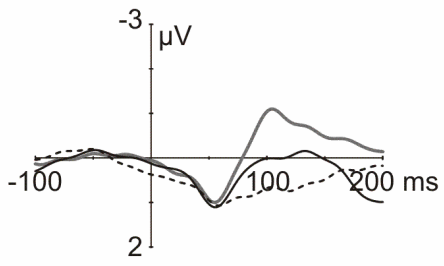

Difference waves:

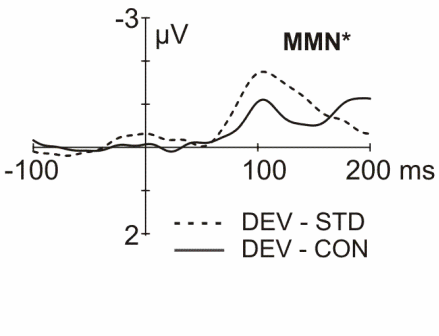


Figure 3. Bar charts showing mean amplitudes of the MLR components (left side) and MMN (right side). Each chart plots the mean values and standard errors of mean for the three stimulus types (standard in light gray, deviant in grey, and control in dark grey) for the $800 \mathrm{~Hz}$ and 3730 $\mathrm{Hz}$ frequencies. Note that, in accordance with Figure 2, positive values are pointing downwards.
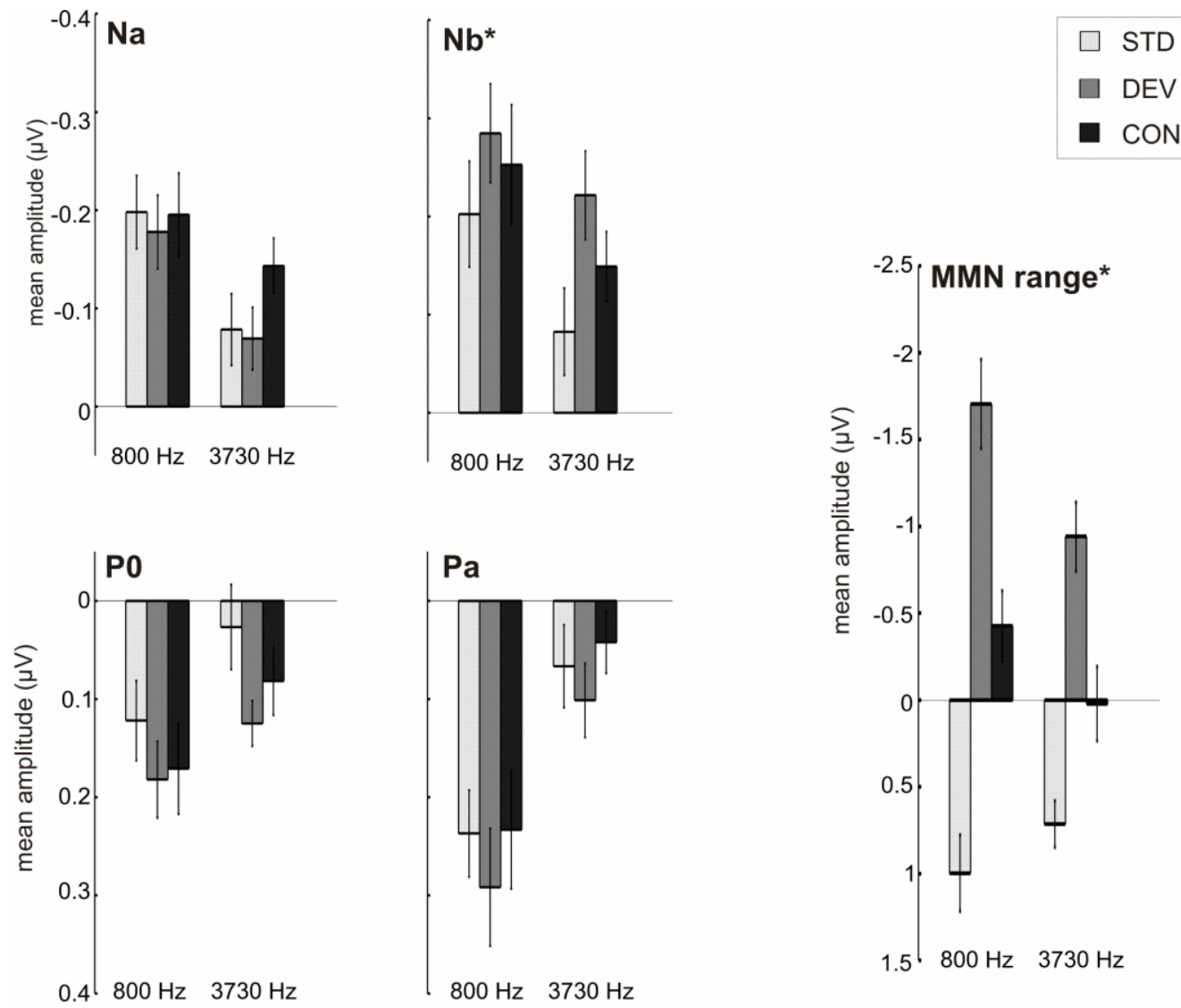
Hierarchical organization of auditory change detection

Table 1. Mean of individual peak latencies for the MLR components $\mathrm{P} 0, \mathrm{Na}, \mathrm{Pa}$, and $\mathrm{Nb}$. Standard Errors of Mean are given in parentheses.

\begin{tabular}{|c|c|c|c|c|c|c|c|c|}
\hline & \multicolumn{2}{|l|}{ PO } & \multicolumn{2}{|l|}{$\mathrm{Na}$} & \multicolumn{2}{|l|}{$\mathrm{Pa}$} & \multicolumn{2}{|l|}{$\mathrm{Nb}$} \\
\hline & \multicolumn{2}{|c|}{$\begin{array}{l}\text { Mean peak } \\
\text { latency (SEM) }\end{array}$} & \multicolumn{2}{|c|}{$\begin{array}{l}\text { Mean peak } \\
\text { latency (SEM) }\end{array}$} & \multicolumn{2}{|c|}{$\begin{array}{l}\text { Mean peak } \\
\text { latency (SEM) }\end{array}$} & \multicolumn{2}{|c|}{$\begin{array}{l}\text { Mean peak } \\
\text { latency (SEM) }\end{array}$} \\
\hline Sta & 13.35 & $(0.49)$ & 24.05 & $(0.44)$ & 32.50 & $(0.48)$ & 43.35 & $(0.45)$ \\
\hline Dev & 13.05 & $(0.33)$ & 24.50 & $(0.29)$ & 33.00 & $(0.36)$ & 43.20 & $(0.58)$ \\
\hline Con & 12.45 & $(0.49)$ & 24.65 & $(0.40)$ & 31.70 & $(0.48)$ & 43.60 & $(0.55)$ \\
\hline \multicolumn{9}{|c|}{ Freq $3730 \mathrm{~Hz}$} \\
\hline Sta & 11.90 & $(0.66)$ & 23.30 & $(0.51)$ & 30.50 & $(0.69)$ & 42.10 & $(0.70)$ \\
\hline Dev & 13.15 & $(0.60)$ & 22.60 & $(0.47)$ & 29.35 & $(0.44)$ & 40.85 & (0.65) \\
\hline Con & 12.05 & $(0.59)$ & 22.85 & $(0.51)$ & 30.50 & $(0.59)$ & 40.80 & $(0.67)$ \\
\hline
\end{tabular}

Table 2. Mean amplitudes of the MLR components $\mathrm{P} 0, \mathrm{Na}, \mathrm{Pa}, \mathrm{Nb}$ derived from a 4-ms latency windows centered around the peak latency in the grand-average waveforms. Standard Errors of Mean are given in parentheses.

\begin{tabular}{|c|c|c|c|c|c|c|c|c|}
\hline \multirow{2}{*}{ Freq $800 \mathrm{~Hz}$} & \multicolumn{2}{|l|}{ PO } & \multicolumn{2}{|l|}{$\mathrm{Na}$} & \multicolumn{2}{|l|}{$\mathrm{Pa}$} & \multicolumn{2}{|l|}{$\mathrm{Nb}$} \\
\hline & \multicolumn{2}{|c|}{$\begin{array}{l}\text { Mean window amplitude } \\
\text { (SEM) }\end{array}$} & \multicolumn{2}{|c|}{$\begin{array}{l}\text { Mean window amplitude } \\
\text { (SEM) }\end{array}$} & \multicolumn{2}{|c|}{$\begin{array}{l}\text { Mean window amplitude } \\
\text { (SEM) }\end{array}$} & \multicolumn{2}{|c|}{$\begin{array}{l}\text { Mean window amplitude } \\
\text { (SEM) }\end{array}$} \\
\hline Sta & 0.122 & $(0.042)$ & -0.198 & $(0.038)$ & 0.237 & $(0.045)$ & -0.203 & $(0.055)$ \\
\hline Dev & 0.182 & $(0.040)$ & -0.178 & $(0.038)$ & 0.292 & $(0.061)$ & -0.285 & $(0.051)$ \\
\hline Con & 0.171 & $(0.047)$ & -0.195 & $(0.043)$ & 0.233 & $(0.062)$ & -0.253 & $(0.062)$ \\
\hline \multicolumn{9}{|c|}{ Freq $3730 \mathrm{~Hz}$} \\
\hline Sta & 0.027 & $(0.044)$ & -0.079 & $(0.037)$ & 0.067 & $(0.043)$ & -0.083 & $(0.046)$ \\
\hline Dev & 0.125 & $(0.024)$ & -0.069 & $(0.033)$ & 0.101 & $(0.039)$ & -0.222 & $(0.046)$ \\
\hline Con & 0.082 & $(0.036)$ & -0.143 & $(0.029)$ & 0.042 & $(0.032)$ & -0.149 & $(0.036)$ \\
\hline
\end{tabular}

